\title{
A Journey in Science: Cell-Cycle Control
}

\author{
Paul Nurse \\ The Francis Crick Institute, London, United Kingdom
}

\begin{abstract}
Real innovations in medicine and science are historic and singular; the stories behind each occurrence are precious. At Molecular Medicine we have established the Anthony Cerami Award in Translational Medicine to document and preserve these histories. The monographs recount the seminal events as told in the voice of the original investigators who provided the crucial early insight. These essays capture the essence of discovery, chronicling the birth of ideas that created new fields of research; and launched trajectories that persisted and ultimately influenced how disease is prevented, diagnosed, and treated. In this volume, the Cerami Award Monograph is by Paul Nurse, Director, The Francis Crick Institute in London, UK. A visionary in the field of cell biology, this is the story of Dr. Nurse's scientific journey.

Online address: http://www.molmed.org

doi: $10.2119 / \mathrm{molmed} .2016 .00189$
\end{abstract}

Quite often days for scientists in the lab can be rather dull but this day was going to be different. We were all huddled around the computer screen as the letters marched across the screen, marking out the predicted protein sequences of the two genes. The computer was slowly matching up the identities and similarities in the amino acids making up the protein sequences encoded by the yeast and human genes we were comparing. Over $60 \%$ of the amino acids were identical, and their overall lengths were only one amino acid different. There was no question that the fission yeast cdc2 cell-cycle control gene, encoding a cyclin-dependent protein kinase, or CDK, and our newly identified human gene were structurally very similar. This similarity, and the fact that the human gene could functionally substitute for the yeast cdc2 gene, meant that these genes were the same, despite up to 1.5 billion years of divergence between the two organisms. And given that the cdc2 gene was central to cell-cycle control in yeast, it was extremely likely that CDKs were controlling cell reproduction by the same mechanism in all eukaryotes, from the humble yeast cell all the way to the cells in human beings. The principles underpinning cell-cycle control worked out in yeast cells had to be much the same in human cells. I experienced a sense of wholeness that the extraordinary diversity of life was built on common principles, and that this advance in understanding of how the cell-cycle was regulated would have many implications for the reproduction, growth and development of all living organisms, and for diseases like cancer. I also felt I was a very lucky scientist.

So how did I become a scientist, why was I working on this problem, and what was the journey that led to this discovery that the CDKs are the major regulators of eukaryotic cell-cycle progression? I think it started when I was a nine-year-old school boy. On my daily walk to school

Address correspondence to Paul Nurse, The Francis Crick Institute, 1 Midland Rd, London NW1 1AT, United Kingdom. Phone: +44(0)20 37962495 ; E-mail: paul.nurse@crick.ac.uk. Published Online (WWw.molmed.org) May 24, 2017.

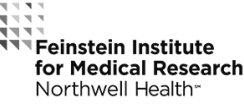

Feinstein Institute Northwell Health 
I became interested in natural history and astronomy and studied the sciences at school. I was not very good at examinations, my home was not at all academic, but my biology teacher Keith Neal was inspirational, helping me set up experiments out of school time. I investigated fish egg development and pigment formation in the eyes of Drosophila using paper chromatography and following protocols out of Scientific American. I was good enough to be considered for University entrance, a first for my family who had all left school before the age of 15 years, but I failed to get a place in any university because of my linguistic ineptitude, which meant I could not pass even the most basic examination in a foreign language, at that time mandatory for all students to enter a UK university. So instead, at 17 years of age, I became a junior technician making up the media in a laboratory attached to the Guinness Brewery in London. My boss, Vic Knivet, let me play around in the lab and do a research project using immunofluorescence to identify bacterial pathogens. Then Birmingham University relented and admitted me to study biology, even though I did not have a foreign language qualification. For the record, I had managed to fail the required French exam six times in succession, which I suspect is close to being a world record. At University, I got better at doing examinations, and switched from my initial interests in evolution and ecology to cell and developmental biology with a focus on plants. So by the end of my first degree I was looking for somewhere to do a PhD, but what should I work on?

My teachers were mainly botanists and I was tending toward doing research into plants but was worried that work with plants would be too slow for a 3-year PhD, and therefore decided to work on faster growing fungi with the intention of switching back to plants when my PhD was finished. I decided to go to the University of East Anglia in Norwich, a small medieval city where I had been born and had lived for a few months as a newborn baby. My supervisor was Tony Sims, a botanist who worked on amino acid metabolism. I set to work on the compartmentation of amino acid pools in the fungus Candida utilis, and then later on how the amino acid pools changed during the cell cycle $(1,2)$. I did not discover anything very interesting during my thesis work, but Tony and my colleague Andres Wiemken taught me something important: how to do good experiments that were controlled and reproducible. And I taught myself something important too: that it was essential to tackle a significant research problem, one that if solved could make a difference. It might not be solved of course, but it had to be a problem that was worth solving, and preferably it should have little to do with amino acid pools.

I was attracted to the cell cycle, which is the basis of growth and reproduction, characteristics central to all living organisms, so understanding how the cell cycle is controlled seemed to be an important problem worth investigating. But how? Lee Hartwell working in Seattle had taken a genetic approach, isolating temperature sensitive mutants of budding yeast that could not complete cell division, thus defining cell division cycle, or cdc, genes $(3,4)$. Murdoch Mitchison was working in Edinburgh and was the world's expert on the fission yeast cell cycle. He had also written what was for me the most interesting book in the area, "The Biology of the Cell Cycle" (5). I read it as a PhD student and was impressed by its directness, its focus on biology and the importance it gave to experiment and data. Within its rather focused arguments there was a vision, not always easy to discern, but in fact a vision that was central to life. I wrote to Murdoch proposing I use genetics to try and investigate cell-cycle control, and he invited me from Norwich to come and visit him in Edinburgh.

On the day of my interview it was wintry and cold, and snow was dusted all over Arthur's Seat, the extinct volcano in the center of the city. I had traveled the 400 miles up to Scotland during the night, sitting up on the train from Norwich. I was nervous to meet the famous professor at the peak of his career, and when ushered into his office I was somewhat daunted by his rather overwhelming presence. But his intense curiosity in research was completely engaging. All he wanted to do was talk, talk about the cell cycle, what it meant to him, what experiments he was doing in the lab (lots on that), what did I want to do when I got there. We talked all day, the great man and the PhD student.

My idea was to apply genetics to the fission yeast cell cycle, following what Lee Hartwell was doing with the budding yeast, although it must be said not many scientists at the time thought that yeasts had much to contribute to understanding the eukaryotic cell cycle. Murdoch knew all about the cell cycle, more about the fission yeast cell cycle than anyone else on the planet, but he was not a geneticist and neither was I. But Murdoch had a plan. Spend half a year with Urs Leupold-in Bern, Switzerland-who was the most distinguished fission yeast geneticist in the world, learn genetics from him and come back to Edinburgh and apply what I had learned to the cell cycle. So that is what I did. When I returned to Edinburgh after my time with Urs, my interactions with Murdoch fell into a regular pattern. Once or twice a week he would ask me into his office to talk. These occasions were never short, they usually would last several hours interspersed by the occasional coffee and by Murdoch's constant puffs on his pipe, both rather intense experiences. The conversations ranged constantly over the cell cycle, what experiments Murdoch was doing with his experimental colleague Jim Creanor, what experiments were being done by others in his lab, including my subsequent lifelong colleagues Peter Fantes and Kim Nasmyth and what experiments I had done that week. Our talks were always close to the data being generated and the ideas that might explain them. The discussions were often not very direct, we circled topics, departed on tangents, became 
distracted in cul-de-sacs. They were nearly always stimulating, often provocative, occasionally rather strange. Murdoch was like a 19th century biologist fascinated by living organisms and the biological phenomena of the cell cycle. Sometimes he did not seem to belong to the second half of the 20th century. But what came through was the passion to want to know, an understated passion, but one that permeated most of our conversations. And then there was his generosity. Despite the constant attention that Murdoch gave me, he was not a co-author on any of the papers that I produced while working with him. Many of the papers I was involved in were collaborative with other co-authors working in his lab, but Murdoch never thought he himself had contributed enough to deserve co-authorship. I am not sure why he thought that, but perhaps it was because he had not contributed with his own hands to the experiments or to the immediate interpretation of data, or maybe he just wanted to help his younger colleagues and felt he could do so best by not putting his name to work carried out in his lab.

The first thing I did when I started doing lab work in Edinburgh was to begin isolating cdc mutants in the rodshaped fission yeast, which grows by extension at its cell ends. This was a laborious and tedious business requiring first the isolation of temperature sensitive mutants and then visual screening for colonies containing elongated cells. These enlarged cells indicated that they could not divide but could still grow, and so were not defective in any of the many processes required for cell growth, defects which could indirectly affect the cell division cycle (5). It was slow work, because only about one in ten thousand of the original mutagenized cells yielded a cdc mutant. As a consequence it took the best part of a year to identify enough mutants to define just 30 cdc genes $^{6}$. It is now known that there are around 400500 cell cycle genes $(7,8)^{7}$, so even this effort had identified only a small fraction of the total needed for the cell cycle.
I wanted to find a selection procedure to reduce this tedious workload, and so hit on the idea of centrifuging cells after mutagenesis through a gradient to enrich for enlarged cells, then examining the microcolonies formed from these cells under a microscope, and finally micromanipulating away elongated cells as potential cdc mutants. This was not as bright an idea as I originally thought, however, because mutagen-damaged deoxyribonucleic acid (DNA) blocks onset of the subsequent mitosis resulting in elongated cells. This is not due to a specific gene defect, but because of nonspecific DNA damage, which affects many cells in the population. I struggled with this procedure for many weeks, finding fewer cdc mutants than by my normal procedure, and was on the verge of abandoning the approach altogether when I spotted something unexpected under the microscope. What I saw was a microcolony made up of small cells, shorter than the normal rod-shaped wild-type fission yeast cells. This was the complete opposite phenotype of the enlarged cells I was searching for. How these small cells got to where they did in the gradient I do not know, given I was using a selection scheme designed to enrich for large cells. I looked at them for a while and then it gradually dawned on me that cells dividing at a small size might be finishing their cell cycle more rapidly than they could grow, and as a consequence were being advanced prematurely through a ratelimiting process of the cell cycle that was controlling the overall rate of cell reproduction. If correct, this small-sized mutant was defining a cell-cycle control of the type that I was interested in. This would be a control that determined the rate at which critical events of the cell cycle were completed, rather similar to pacemaker enzymes in metabolic pathways that determined the rate of flux of metabolites through the pathway. I was familiar with this from Henry Kascer, who studied the regulation of metabolic flux in Edinburgh.

This first mutant, which I called "wee," a name I thought witty at the time (although the wit wears thin after nearly half a century) because it was small and isolated and I was in Scotland, was by chance temperature sensitive. This meant it was of normal size at low temperature and small at high temperature. Following discussion with Peter Fantes, we worked out that by shifting temperatures it would be possible to determine when in the cell cycle cells become advanced, and so establish what step was rate limiting for progression through the cell cycle. This revealed that wee1 acted at the G2 to mitosis transition, so the gene was determining the length of G2 and thus the onset of mitosis $(9,1-)^{9}$. This was a surprise because at the time most researchers thought that rate-limiting cell-cycle controls would act at the beginning of the cell cycle in G1.

I decided to look for more wee mutants to define the rate-limiting steps of the cell cycle and the genes acting in these controls. I set myself the target of finding 50 wee mutants for this analysis. This search was even more tedious than the search for cdc mutants because wee mutants were even rarer. For much of the next year I isolated new mutants, checking as I went along whether they were alleles of wee1, or as I hoped, mutants which defined new genes and controls. About one or two new mutants were found every week but all were alleles of wee1. I was making little progress. Near the end of my frustrating quest, I spotted wee mutant 48 , but unfortunately it was on a plate covered with a filamentous fungus. It is difficult to purify a yeast strain away from a contaminating fungus which spreads much more rapidly across an agar plate. Also, it was late afternoon on a cold, rainy, Scottish November Friday. I was tired at the end of the week and convinced this mutant was yet another allele of wee1, which would only swell my collection from 47 to $48 \mathrm{mu}$ tants defective in wee1. I threw it away in the rubbish and went home.

And then I felt guilty. What if this mutant was special? Perhaps it defined something new and different, rather than yet another allele of wee1. I finished my dinner and got back on my bicycle (it 
was dark and still raining) and cycled back to the lab. Delving into the rubbish I found the plate and started the long process of subculturing the yeast away from the continually invading fungus. Eventually I got a pure culture of the new wee mutant, crossed it with my wee1 alleles, and found it was a new gene unlinked to wee1! I called it "wee2," which of course sounds even sillier than wee1.

So now there were two genes involved in cell-cycle control, wee1 and wee2. This was the 1970s, before cloning, so the only experimental approaches possible had to be based on classical genetics. Out of 50 wee mutants 49 were alleles of wee1, one of wee2. That suggested that wee1 encoded an inhibitor of the G2 to mitosis transition because loss of function mutations can be expected to be frequent. Given that only one wee2 mutation had been isolated, perhaps wee 2 encoded an activator and the wee 2 mutation made that activator more active. Such a positive acting gain of function change could be expected to be rare. But it would also mean that a loss of function wee2 mutation would fail to complete the cell cycle. So possibly one of the cdc mutations that had already been isolated might define a cdc gene which could be hyperactivated to generate the wee2 phenotype. It was just possible that the equivalent cdc gene had already been identified. This was unlikely, however, as the 30 genes identified represented only a small fraction of the total cdc genes that were to be expected (8). But perhaps it was worth checking.

So I crossed the wee2 mutant to representative alleles of each of the $30 \mathrm{cdc}$ genes, and I was lucky: wee2 was closely linked to cdc2. I explained all of this to my colleague and genetic guru, Pierre Thuriaux, but he said it was possible that wee2 was not the same gene as cdc2 but was simply adjacent to cdc2 or very nearby. How could this be solved using classical genetics? The only way was to construct a fine structure map of cdc2 and to map the wee 2 mutant allele onto that map. This was another very slow project. New cdc2 alleles had to be found and mapped, linkage had to be determined, a fine structure map had to be made and finally wee 2 had to be mapped onto the cdc2 gene map. Another year went by, a mind-numbing grind carried out with Pierre, that eventually showed that the wee 2 allele did indeed map within the cdc2 gene. So wee1 and cdc2 acted as negative and positively acting regulators functioning in the major rate-limiting step of the fission yeast cell-cycle acting at the G2 to mitosis transition (11).

I was really pleased with this result. But there was a problem. Unfortunately the world was not as interested as I was in this result, because most attention was still on cell-cycle controls acting in G1. This was a particular problem for me because by now I had two small children and a mortgage, and my post-doc employment was coming to an end. I was still in Edinburgh working in Murdoch Mitchison's lab, who was incredibly supportive but had no long-term salary possibilities for me, and I now had a family to support. I had to find a job and with the lack of interest in G2 cell-cycle controls I thought I had better do some work on G1. But what could I do? Once again Lee Hartwell came to my rescue. He had defined a G1 control called "start" revealed by clever studies with his budding yeast cdc mutants. He had taken a developmental biologist's approach, asking at what point in the cell cycle did cells become "committed" to that cell cycle in the sense that alternative developmental pathways to the cell cycle are no longer possible. He had arrested cdc mutants at different stages of the cell cycle and challenged them to undergo the alternative developmental pathway of conjugation. Those before commitment, the point of no return, could conjugate, while those after could not. $\mathrm{He}$ called this control "start" and identified several start genes, one of which was called CDC28 $(12,13)$.

I thought it would be easy for me to do a similar analysis in fission yeast, and so I could make a contribution, albeit a minor one, to G1 cell-cycle control. If successful, perhaps I could even get a job. So I set up an assay system and quite rapidly made progress. Most of the cdc mutants blocked at a stage where they failed to conjugate, but I found one blocking in early G1 that conjugated very efficiently. This mutant defined cdc10, which encoded a protein that was eventually found to be a transcription factor required for DNA replication. This gene acted prior to commitment, and so extended the start concept to fission yeast. My very last experiment before publishing was to test the mutants in cdc2, the best studied cdc gene. These mutants blocked in G2 and so would be way past the start commitment point in G1. It was my negative control.

But my negative control did not work. Cdc2 mutants blocked at their restrictive temperature could still conjugate, not that efficiently, but around 20-25\%. I desperately wanted to ignore this result but the figure of 20-25\% was rather high. How could I explain what was obviously an incorrect result? Perhaps the temperature of the water bath being used to block the cdc2 mutants was not correct. I find biologists often blame the temperature when experiments do not work. So I checked the water bath, repeated the experiment, and got $25 \%$ again. I bought a bigger thermometer, checked the temperature of the water bath, repeated the experiment and once again got $25 \%$. I got depressed, stopped doing experiments for a month, did the experiment again and still got $25 \%$.

I was in a dilemma. Everything else had worked perfectly, either no conjugation, or conjugation, but what did an intermediate result of $25 \%$ mean? If I reported this intermediate result in my research paper I was certain that it would undermine the other results and the paper would be rejected. What would I do then about my job, paying the mortgage, feeding my babies? Bad thoughts began to enter my mind. Perhaps I should just forget about the cdc2 results. That would be easy to do, as only I knew about them and if I did 
that then perhaps I could get my paper published. Fortunately, I soon realized that this was unacceptable. I kept racking my brain for why I was not getting the "right" result. Then I had a new thought. What if $25 \%$ was actually the correct result? I had never thought of that before, I had always assumed it must be wrong. So if $25 \%$ was right, how could it be explained?

It came to me a few days later, and once thought of, it was obvious. If cdc2 was required twice during the cell cycle in G2 for mitosis as already shown, but also in G1 before S-phase, then a value of $25 \%$ might be explained. Because G1 is short in fission yeast, when arresting a population of cells only a small part of the population blocks in G1. These days a fluorescent activated cell sorter (FACS) would sort this out immediately, but then these machines were not generally available. To test this possibility I arrested cells in G1, and released them into the cdc 2 block. To my relief they all remained blocked in G1 and could conjugate very effectively, so they were all blocked before start. This meant cdc2 had two roles in the cell cycle, both of them controlling. The first acted at the commitment control start in G1 (14) and the second acted in the rate-limiting control acting at G2 determining the onset of mitosis. I was now very excited indeed and I had also learned an important lesson. I had been convinced that I knew the "right" answer so when the "wrong" answer came along I had assumed the experimental result was incorrect. The lesson I learned was always to take results seriously and never sweep uncomfortable results under the carpet.

The coming together of the G1 commitment and the G2 mitosis controls showed that cdc2 was crucial for understanding how the cell cycle is controlled. But there were two difficulties. The first was that the understanding I had come to was very abstract, couched in terms of concepts and gene names but lacking any molecular mechanism. The second was that it applied to fission yeast which, although dear to my heart, was of rather limited interest to the rest of the world. Both problems could be tackled through molecular genetics. If the cdc2 gene could be cloned, its function could then be investigated in molecular terms and comparisons made more easily with other organisms. By this time I had moved to the University of Sussex in Brighton, where I had set up a small lab as an independent researcher but was employed on yet another shortterm contract with no opportunity for tenure. What needed to be done to clone the cdc2 gene was to develop molecular genetic procedures for fission yeast. I made the strategic decision to abandon cell-cycle research for a while and to develop DNA transformation methods, plasmid vectors, gene libraries and gene manipulation techniques, all necessary if cdc2 was to be cloned and biochemically investigated. This was made much easier because of an European Molecular Biology Organization (EMBO) cloning course I attended at European Molecular Biology Laboratory (EMBL), and because of a colleague at Sussex, David Beach, who had gene cloning experience. The first task was to get DNA transformation to work, the starting point being the methods successfully developed to transform budding yeast which had been achieved the year before. The two yeasts are rather distantly related, but after some tinkering, the basic components of the budding yeast vector systems were found to work in fission yeast. Trickier were the manipulations needed to get DNA into the fission yeast cells.

The transformation procedure that worked with budding yeast required the generation of protoplasts. A different procedure was needed to make fission yeast protoplasts which worked well, but getting efficient regrowth of cell walls after bathing the protoplasts in DNA was more difficult. The most promising approach was to resuspend the protoplasts in soft agar, and then pour this onto a prepared nutrient containing plate. The first experiment I carried out was totally chaotic. I had chosen the wrong agar and it partly set in the tubes, containing the protoplasts before plating. All I could do was shake the semisolid agar out of the tubes onto the plates, like getting sauce out of the bottom of a bottle. The lumps on the petri dish had to be flattened with the plate lid, a complete and utter mess. Time to put the plates in the incubator, abandon the experiment and go home. Three days later there were microcolonies in the remains of the soft agar. I thought they must be contaminants, but they were not; they were fission yeast and within a few days could be shown to be DNA transformants $(15,16)$. Now the cdc2 gene could be cloned.

To clone cdc2, the approach was to use a fission yeast DNA library and to look for a plasmid that could rescue a temperature sensitive cdc2 mutant. The first library made of fission yeast genes only yielded a suppressor of cdc2 called suc1 (17), but the second library we made worked, and yielded cdc2 itself (18). This was a great moment. We had the physical presence of the cdc2 gene on a $2 \mathrm{~kb}$ DNA fragment in an Eppendorf tube. All the previous abstraction could now become more concrete. At this time, sequencing even such a small fragment such as $2 \mathrm{~kb}$ took many months, so in the meantime we decided to use the same approach of cloning by rescue of a cdc 2 mutant, but this time using a budding yeast library to see if the same gene existed in budding yeast. To my surprise clones grew up; it appeared that a gene equivalent to cdc2 might exist in budding yeast. Perhaps cell-cycle control was conserved, at least among simple eukaryotes.

The question was: which budding yeast gene was it? Only 4 cdc genes had been cloned from budding yeast (19) by Steve Reed and Kim Nasmyth and they generously sent them so we could test if one of them was the gene we had cloned. Once again we had no right to be so lucky given there are over 5,000 genes in yeast, but by Southern blotting we showed that the fission yeast cdc2 gene was the same as the budding yeast CDC28 gene (18). This was one of the 4 genes Steve had cloned and the one that Lee had shown acted at the G1 commitment controls. It was uncanny how it was all falling into place. Then the cdc2 
sequence was completed (20). There was a hit in the database - the src oncogene, thought to encode a protein kinase. So did the cdc2 also encode a protein kinase? Steve Reed was asking the same question about CDC28 $(21,22)$. This required making antibodies against the protein encoded by the cdc2 gene.

The approach chosen by Viesturs Simanis, a new post-doc in the lab, was to express cdc2 in E. coli, purify the protein made, and inject it into rabbits to make antibodies. This approach had been used before but not very much. Once we had antibodies, Viesturs immune-precipitated the cdc2 protein out of fission yeast cell extracts and set up in vitro protein kinase assays. The substrate that worked, although not very well, was casein. This is a milk protein irrelevant for the cell cycle in yeast, but at least it generated a protein kinase phosphorylation signal. To demonstrate it was really cdc2 specific, we showed that an extract made from a temperature-sensitive cdc2 mutant generated temperature-sensitive protein kinase activity in vitro (23). Then Sergio Moreno in the lab optimized the assay conditions and showed that the cdc2 protein kinase activity rose during the cell cycle peaking at mitosis, indicating that protein phosphorylation was key to cell-cycle control4 (3). Next, Paul Russell cloned two regulators of cdc2, the inhibitor Wee1 and the activator cdc25, and demonstrated that Wee1 was a protein kinase $(25,26)$. Finally, Kathy Gould, with heroic in vivo $\mathrm{P}^{32}$ labeling experiments, showed that cdc2 was phosphorylated on a tyrosine located at the ATP binding site, which became dephosphorylated as cells entered mitosis, presumably modulated by Wee1 and cdc25 (27). These were a remarkable quartet of post-docs who got the basic regulatory network for mitotic control essentially correctly worked out.

I was happy to continue working with fission yeast to work out the details of this control. But I was also wondering if the control was conserved in all eukaryotes. Budding and fission yeast are not very closely related, so if there was conservation between these yeasts perhaps there was a cdc2 in humans too. Working at the Imperial Cancer Research Fund in London, I was always being asked by my senior colleagues if cell-cycle control was the same in human cells. But I was nervous of wasting my lab colleagues' time on such an obviously long-shot project. Then a bold post-doc, Melanie Lee, came to my lab and asked for a difficult project. We decided that looking for cdc2 in human cells would be sufficiently difficult, especially given that the last common ancestor between the yeasts and humans may have been around 1.5 billion years ago, quite a long time for conservation to be maintained.

Melanie started by looking for DNA fragments from human cells that were structurally similar to the fission yeast cdc2 gene using two approaches: first using antibodies against the yeast protein combined with a human expression library, and second using reduced stringency Southern blotting. It is important to remember there were no whole genome sequences, no polymerase chain reaction (PCR) and only limited gene libraries. It was a very hard project for Melanie, with occasional leads not going anywhere. It also inherently seemed unlikely to work, given the huge divergence between humans and yeast, and the fact that there were hundreds of different protein kinases; how would it be possible to know if the correct one had been identified given the evolutionary divergence? The only certain way to show that a candidate human gene had the same function as cdc2 was to establish whether it could rescue a fission yeast cdc2 mutant. Therefore the way to go forward was to clone by rescue, just as CDC28 had been cloned.

A good human cDNA library was generously given by Hirota Okayama and Paul Berg, which by chance could be expressed in fission yeast. Melanie went to work. Many Petri dishes later, a clone derived from a cdc2 temperature-sensitive mutant was found to be growing at high temperature. But was it a contaminant, a revertant, a plasmid that had picked up a yeast gene or a human gene acting as a suppressor? Checking all of these possibilities was probably the most stressful period of my working life, because if this growing clone did indeed contain the human cdc2 gene, then it was likely that cell-cycle control was common to all eukaryotes, and that was important. As every week passed, each experiment eliminated yet another trivial explanation. However, I was very concerned that the clone would eventually be shown to be an artifact. I began to dread going to the lab in case the experiment of that day would show that we had failed. Melanie always seemed to be calm but I was not. I began to imagine that it was true just so I could savor a successful outcome if only for a couple of days, which would then be dashed the next week. As we eliminated more and more of the trivial explanations, the worse it became. Eventually we were on the edge, we knew that it was a human DNA segment that was rescuing the cdc2 temperaturesensitive mutant, but was it just a high copy number suppressor or was it a human homologue of cdc2? The DNA sequence and the translated protein sequence were the final test, and that led to us all being huddled around the computer I described at the beginning of this account (28). And what do I remember most about that evening? An overwhelming relief that it was all true.

So how do the implications of knowing better how the cell cycle is controlled translate into benefits for society? Social benefits fall into two categories: very significant advances in general human understanding of the natural world and the potential to improve the human condition through useful applications. A major intellectual advance of the cellcycle control work was the linking of the process of cell division to the molecular mechanisms underpinning the replication of the hereditary material centered on the double helical structure of DNA and complementary DNA strand synthesis. This linkage is crucial to all life. The cell is the simplest entity exhibiting the 
properties of life, and one of the most important of these properties is reproduction. The growth and reproduction of all living organisms is based on the cell cycle, which requires the co-ordination of S-phase, with mitosis. This involves the proper initiation of both S-phase and mitosis, and the correct co-ordination of these events with each other, which is what the CDKs do. They are required at key steps initiating S-phase and mitosis, and also during G2 to block a further initiation of S-phase until the completion of mitosis. This third function ensures there are no changes in ploidy during a properly regulated cell cycle, and this was identified in fission yeast by my colleagues Sergio Moreno and Jacqueline Hayles. They respectively showed that either overexpressing the CDK inhibitor Rum1 (29) or deleting the CDK cyclin activator Cdc13 (30) both resulted in the reinitiation of S-phase once CDK activity had been sufficiently reduced. In most eukaryotes there is a family of CDKs engaged in these controls, although more recent work from Damien Coudreuse in my lab has shown that for fission yeast, a single CDK can carry out all these controlling roles (31). The CDKs provide the link between the chemistry of the hereditary process, which is the molecular replication of DNA, and the biology of the hereditary process, which results in cell division. Another intellectual advance is the recognition that many biological processes, even those as complex as the cell cycle, are highly conserved from simple unicellular eukaryotes, such as yeast, to complex metazoans such as ourselves. The cell cycle is a good example of this conservation, although it is also clear that it applies to many fundamental biological processes. The implication of this is that the study of biological phenomena in experimentally amenable model systems, such as the yeasts, worms, flies, fish and mice can be very revealing about related phenomena in human beings. However, it is surprising how frequently this conclusion is forgotten.

The potential to bring about useful applications as a consequence of improved knowledge of the cell cycle is mostly in the arena of cancer. Cancer arises when there is uncontrolled cell division due to damage to the controls regulating the growth of cells and their subsequent reproduction. Without understanding the networks of CDKs and their regulation, it is difficult to have the necessary conceptual framework required to think properly about what causes cancer and how it may be treated. This is because CDKs bring about the key events of the cell cycle and ultimately these have to be inappropriately activated for cancer to occur. Also some types of genetic damage that can bring about cancer are a consequence of aberrant cell-cycle controls, which involves the CDKs. If DNA is damaged or DNA replication is incomplete, then that genetic damage will be inherited by the newly divided cells. This either results in cell death or can lead to changes in the functioning of genes important for cell growth and reproduction, which result in cancer. To prevent this cells have checkpoint controls, whereby DNA damage or incomplete replication signals a block over mitosis until the genetic damage is repaired. This block over mitosis is usually brought about by the phosphorylation of a tyrosine residue in cdc2 due to the Wee1 protein kinase activity. WEE1 is the human homologue of the fission yeast wee1 gene defined by the very first wee mutants that were isolated. Knowledge of these molecular mechanisms is required to fully understand how cancer arises and to develop certain therapeutic interventions. In addition, some CDKs in metazoans have been shown to be important for cell growth as well as cell reproduction, and so are also relevant to this aspect of the controls that become dysregulated in cancer. The CDK network and their regulators are being investigated to determine if their inhibition may bring about therapeutic interventions for the treatment of cancer. One of these regulators is WEE1, and a potent inhibitor of the human WEE1 kinase has been developed by Merck. Because p53 deficient tumors rely on the DNA damage checkpoint to survive, it was thought that by inhibiting WEE1 these tumor cells should be sensitized to DNA damage. This inhibitor is being tested in a number of clinical trials in combination with DNA damaging agents, with future work being developed by AstraZeneca. There is hope that these interventions may provide new ways to treat cancer, particularly in combination therapy.

There have been clear translational benefits of understanding cell-cycle control better, resulting in improved human understanding of the natural world and in thinking more effectively about cancer and new possible ways to treat cancer. The humble fission yeast turned out to be quite useful after all.

\section{ACKNOWLEDGMENTS}

I want to thank Jacky Hayles for critically reading this manuscript and Tim Humphreys for information on Wee1 cancer therapy. The middle part of this account is based on my essay Learning from the Uncontrollable, Cell, 165 (p1301-1306) (2016). This article is dedicated to all my lab colleagues that I have had the privilege to work with. This work was supported by the Francis Crick Institute which receives its core funding from Cancer Research UK (FC01121), the UK Medical Research Council (FC01121), and the Wellcome Trust (FC01121). In addition this work was supported by Wellcome Trust Grant [grant number 093917], The Breast Cancer Research Foundation and The Rockefeller University.

\section{DISCLOSURE}

The authors declare that they have no competing interests as defined by Molecular Medicine, or other interests that might be perceived to influence the results and discussion reported in this paper.

\section{REFERENCES}

1. Wiemken A, Nurse P (1973) Isolation and characterisation of the amino acid pools located with the cytoplasm and vacuoles of Candid utilis. Planta. 109:293-306.

2. Nurse P, Wiemken A. (1974) Amino acid pools and metabolism during the cell division cycle 
of arginine grown Candida utilis. J. Bacteriol. 177:1108-16.

3. Hartwell LH. (1971) Genetic control of the cell division cycle in yeast II. Genes controlling DNA replication and its initiation. J. Molec. Biol. 59:183-94.

4. Hartwell LH, Mortimer RL, Culotti J, Culotti M. (1973) Genetic control of the cell division cycle in yeast V. Genetic analysis of cdc mutants. Genetics. 74:267-86.

5. Mitchison JM. (1971) The Biology of the Cell Cycle. Cambridge: Cambridge University Press.

6. Nurse P, Thuriaux P, Nasmyth K. (1976) Genetic control of the cell division cycle in the fission yeast Schizosaccharomyces pombe. Mol. Gen. Genet. 146:167-78.

7. Kim DU, et al. (2010) Analysis of a genome-wide set of gene deletions in the fission yeast Schizosaccharomyces pombe. Nat. Biotechnol. 28:617-23.

8 Hayles J, et al. (2013) A genome-wide resource of cell cycle and cell shape genes of fission yeast. Open Biol. 3:130053.

9. Nurse P. (1975) Genetic control of cell size at cell division in yeast. Nature. 256:547-51.

10. Fantes P, Nurse P. (1977) Control of cell size at division in fission yeast by growth-modulated size control over nuclear division. Exp. Cell Res. 107:377-86.

11. Nurse P, Thuriaux P. (1980) Regulatory genes controlling mitosis in the fission yeast Schizosaccharomyces pombe. Genetics. 96:627-37.

12. Hartwell LH. (1974) Saccharomyces cerevisiae cell cycle. Bacteriol. Rev. 38:164-98

13. Pringle J, Hartwell L. (1981) The Saccharomyces cerevisiae cell cycle. In: The Molecular Biology of the Yeast Saccharomyces. Strathern J, Jones E, Broach J (eds.) Cold Spring Harbor Laboratory, New York, pp. 97-142.

14. Nurse P, Bissett $Y$. (1981) Gene required in $G_{1}$ for commitment to cell cycle and in $\mathrm{G}_{2}$ for control of mitosis in fission yeast. Nature. 292:558-60.

15. Beach D, Nurse P, Egel R. (1982) Molecular rearrangement of mating-type genes in fission yeast. Nature. 296:682-93.

16. Beach D, Piper P, Nurse P. (1982) Construction of a Schizosaccharomyces pombe gene bank in a yeast bacterial shuttle vector and its use to isolate genes by complementation. Mol. Gen. Genet. 187:326-29.

17. Hayles J, Beach D, Durkacz B, Nurse P. (1986) The fission yeast cell cycle control gene $c d c 2$ : isolation of a sequence $s u c 1$ that suppresses $c d c 2$ mutant function. Mol. Gen. Genet. 202:291-93.

18. Beach D, Durkacz B, Nurse P. (1982) Functionally homologous cell cycle control genes in budding and fission yeast. Nature. 300:706-09.

19. Nasmyth K, Reed S. (1980) Isolation of genes by complementation in yeast: molecular cloning of a cell cycle gene. Proc. Natl. Acad. Sci. U. S. A. 77:2119-23.

20. Hindley J, Phear G. (1984) Sequence of the cell division gene $\mathrm{cdc}^{+}$from Schizosaccharomyces pombe, patterns of splicing and homology to protein kinases. Gene. 31:129-34.
21. Lorincz A, Reed S. (1984) Primary structure homology between the product of yeast cell division control gene $\mathrm{CDC} 28$ and vertebrate oncogenes. Nature. 307:183-5.

22. Reed S, Hadwiger J, Lorincz A. (1985) Protein kinase activity associated with the product of the yeast cell division cycle gene CDC28. Proc. Natl. Acad. Sci. U. S. A. 82:4055-9.

23. Simanis V, Nurse P. (1986) The cell cycle control gene $c d c 2^{+}$of fission yeast encodes a protein kinase potentially regulated by phosphorylation. Cell. 45:261-8.

24. Moreno S, Hayles J, Nurse P. (1989) Regulation of $\mathrm{p} 34^{\text {cdc2 }}$ protein kinase during mitosis. Cell. 58:361-72.

25. Russell P, Nurse P. (1986) Cdc25 functions as an inducer in the mitotic control of fission yeast. Cell. 45:145-53.

26. Russell P, Nurse P. (1987) Negative regulation of mitosis by $w e e 1^{+}$, a gene encoding a protein kinase homolog. Cell. 49:559-67.

27. Gould K, Nurse P. (1989) Tyrosine phosphorylation of the fission yeast $c d c 2^{+}$protein kinase regulates entry into mitosis. Nature. 342:39-45.

28. Lee MG, Nurse P. (1987) Complementation used to clone a human homologue of the fission yeast cell cycle control gene $c d c 2$. Nature. 327:31-5.

29. Moreno S, Nurse P. (1994) Regulation of progression through the G1 phase of the cell cycle by the rum $1^{+}$gene. Nature. 367:236-42.

30. Hayles J, Fisher D, Woollard A, Nurse P. (1994) Temporal order of S-phase and mitosis in fission yeast is determined by the state of the $\mathrm{p} 34^{\text {cdc2 }}$ mitotic B cyclin complex. Cell. 78:813-22.

31. Coudreuse D, Nurse P. (2010) Driving the cell cycle with a minimal CDK control network. Nature. 468:1074-9.

Cite this article as: Nurse P, (2017) A journey in science: Cell-cycle control. Mol. Med. 23:112-9. 